\title{
Characterization by Transformation of an Ampicillin-resistant Mutant of Pneumococcus
}

\author{
By L. O. BUTLER AND M. B. SMILEY \\ Department of Medical Microbiology, St George's Hospital Medical School, \\ London S.W.I
}

(Accepted for publication 9 January 1970)

SUMMARY

Mutagenesis of a transformable strain of pneumococcus by $N$-methyl- $N^{\prime}$ nitro- $N$-nitrosoguanidine produced several mutants resistant to ampicillin. One of these was resistant to $0 . \mathrm{I} \mu \mathrm{g}$. ampicillin $/ \mathrm{ml}$., but a purified solution of its DNA transformed the sensitive parent to three different levels of resistance at frequencies compatible with single, double and triple transformants. The higher levels of resistance were dependent on the presence of the genes conferring the lower resistances. Furthermore, transformants to the higher levels of resistance can be obtained at single or double frequency by using as recipient the strain already possessing the genes conferring the lower resistances. The expression times of the ampicillin genes are short (approximately $25 \mathrm{~min}$.), but the actual times were difficult to determine since there was a delay of some I5 to $20 \mathrm{~min}$. before the ampicillin exerted an effect on the sensitive strain under these conditions.

\section{INTRODUCTION}

In the course of experiments designed to map the relative positions of genes on the pneumococcus chromosome, it became necessary to make and characterize new markers to add to those already available. For this purpose, mutagenesis by $N$-methyl- $N^{\prime}$ nitro- $N$-nitrosoguanidine (NNG) was performed and mutants having auxotrophic properties or antibiotic resistances were looked for. Amongst these were mutants resistant to ampicillin, and the characteristics relating to the transforming properties of one of these are described below.

\section{MATERIALS AND METHODS}

Organisms. Diplococcus pneumoniae strain $\mathrm{Cl}$ 3, derived from strain R36A of Avery, MacLeod \& McCarty (1944) by Ephrussi-Taylor (I95I), sensitive to streptomycin and ampicillin. Stock cultures were kept as previously described (Butler, 1965).

Diplococcus pneumoniae strain $\mathrm{r}_{2} \mathrm{SQ}$, derived from strain $\mathrm{r}_{2}$ of Ravin and Iyer (I96I) by transformation, carrying the ery-r2, str-4I, and opt-r2 genes giving resistance to erythromycin, streptomycin and optochin respectively.

Media. The peptone media ' $\mathrm{P}$ ' and 'NS' were prepared as previously described (Sicard, 1965; Butler, 1965), and the synthetic medium of Sicard (1965) was used in the mutagenic reaction with the following additions: glutamic acid $80 \mathrm{mg} . / 1$., aspartic acid $95 \mathrm{mg}$./1., tryptophan $100 \mathrm{mg} . / \mathrm{ml}$., serine $125 \mathrm{mg}$./1., proline $200 \mathrm{mg}$./l., phenylalanine $250 \mathrm{mg}$. $/ \mathrm{l}$., adenine $18 \mathrm{mg}$. $/ \mathrm{l}$. These compounds were added to allow the survival of auxotrophs. 
Ampicillin. A fresh solution of ampicillin ('Penbritin', Beecham Research Laboratories, England) in $0.15 \mathrm{M}-\mathrm{NaCl}$ at the required dilution was prepared for each experiment.

Mutagenesis with NNG. Mutagenesis was obtained by allowing the NNG to act on an exponentially growing culture of strain $\mathrm{Cl} 3$. The organism was first grown in ' $P$ ' medium, washed and resuspended in supplemented Sicard medium. An aliquot of $1 \cdot 0 \mathrm{ml}$. of this suspension was inoculated into $20 \mathrm{ml}$. supplemented Sicard medium and incubated at $37^{\circ}$. NNG at a final concentration of $20 \mu \mathrm{g} . / \mathrm{ml}$. was added at $50 \mathrm{~min}$. and treatment was continued for $30 \mathrm{~min}$. Under these conditions the NNG allowed $50 \%$ survival of the culture. Samples were removed and plated in nutrient agar, incubated at $37^{\circ}$ for $2 \mathrm{hr}$ and a top layer of nutrient agar added containing ampicillin to give a final concentration of $0.025 \mu \mathrm{g} . / \mathrm{ml}$. The strain $\mathrm{Cl} 3$ is sensitive to ampicillin at a concentration of $0.0125 \mu \mathrm{g} . / \mathrm{ml}$. A check that the conditions gave good mutagenesis was provided by testing for the appearance of aminopterin-resistant mutants; if conditions are good, aminopterin-resistant mutants are obtained in high numbers (A. M. Sicard, private communication).

Preparation of deoxyribonucleic acid $(D N A)$. The appropriate strain was inoculated into $750 \mathrm{ml}$. of medium containing I \% (w/v) neopeptone (Difco), $0.85 \%(\mathrm{w} / \mathrm{v})$ yeast extract (Difco), $0.85 \%(\mathrm{w} / \mathrm{v}) \mathrm{NaCl}, 0.5 \%(\mathrm{w} / \mathrm{v})$ glucose and $31.5 \%(\mathrm{w} / \mathrm{v})$ glutamine $(\mathrm{pH} 7 \cdot \mathrm{I})$ and incubated at $37^{\circ}$. After $2 \frac{1}{2} \mathrm{hr}$ phenol red solution was added, and as growth proceeded the lactic acid produced was neutralized by the addition of sodium hydroxide solution. When about $40 \mathrm{ml}$. of $\mathrm{N}$-sodium hydroxide had been added, $55 \mathrm{~g}$. hydrated sodium citrate was added and when dissolved, the culture was lysed by adding $4.5 \mathrm{~g}$. sodium desoxycholate dissolved in a little water and incubated at $37^{\circ}$ for $30 \mathrm{~min}$. One volume of ethyl alcohol was stirred into the lysed culture, and the threads collected. Protein was removed by repeated shaking with chloroform and sec-octyl alcohol (Sevag, Lackman, \& Smolens, 1938), the DNA again precipitated with one volume of ethyl alcohol and the fibres dissolved in sterile $0.15 \mathrm{M}-\mathrm{NaCl}$.

Preparation of lysates. The organism was grown for about $2 \mathrm{hr}$ in $10 \mathrm{ml}$. ' $\mathrm{P}$ ' medium supplemented with asparagine and glutamine, centrifuged and resuspended in $\mathrm{I} \cdot 0 \mathrm{ml}$. of the same medium. To the homogeneous suspension was added $0.1 \mathrm{ml}$. of $5 \%(\mathrm{w} / \mathrm{v})$ sodium desoxycholate and incubated at $37^{\circ}$ for $30 \mathrm{~min}$. The lysates were then kept at $4^{\circ}$ until required, and their activity remained stable for several weeks.

Assay of transforming activity. The method used was essentially as described previously (Butler, 1965); differences in the technique which eventually arose will be described below.

\section{RESULTS}

Isolation of ampicillin-resistant mutants. As a result of the treatment with NNG, several colonies were isolated resistant to ampicillin at the challenging concentration of $0.025 \mu \mathrm{g} . / \mathrm{ml}$. Sensitivity curves were constructed, and the organisms were found to fall into two groups showing resistance to either $0.1 \mu \mathrm{g} . / \mathrm{ml}$, , or $0.05 \mu \mathrm{g} . / \mathrm{ml}$. Strain Amp3, which fell into the first group, was selected for further study.

Transformation with Amp 3 as donor. Transformation was carried out by using purified DNA prepared from the mutant strain Amp 3 as donor and strain $\mathrm{Cl}_{3}$ as recipient. Since mutants of lower resistance had been isolated it was of interest to ascertain whether the DNA from Amp 3 could give transformants resistant only to 
$0 . \mathrm{I} \mu \mathrm{g} . / \mathrm{ml}$. or whether it was also able to transform to lower resistances. After exposure to the DNA, aliquots of the culture were plated in nutrient agar and allowed to express for $2 \mathrm{hr}$ before challenging with several concentrations of ampicillin. The results, given in Fig. I, showed that the DNA transformed to three levels of resistance, $0.03 \mu \mathrm{g} . / \mathrm{ml} ., 0.06 \mu \mathrm{g} . / \mathrm{ml}$. and $0.09 \mu \mathrm{g} . / \mathrm{ml}$. Transformants at the 03 level were obtained at a frequency some $10^{2}$ greater than those at the 06 level, which themselves occurred at a frequency some $10^{2}$ greater than those at the 09 level, indicating that these three levels of resistance were the result of single, double and triple transforming events respectively.

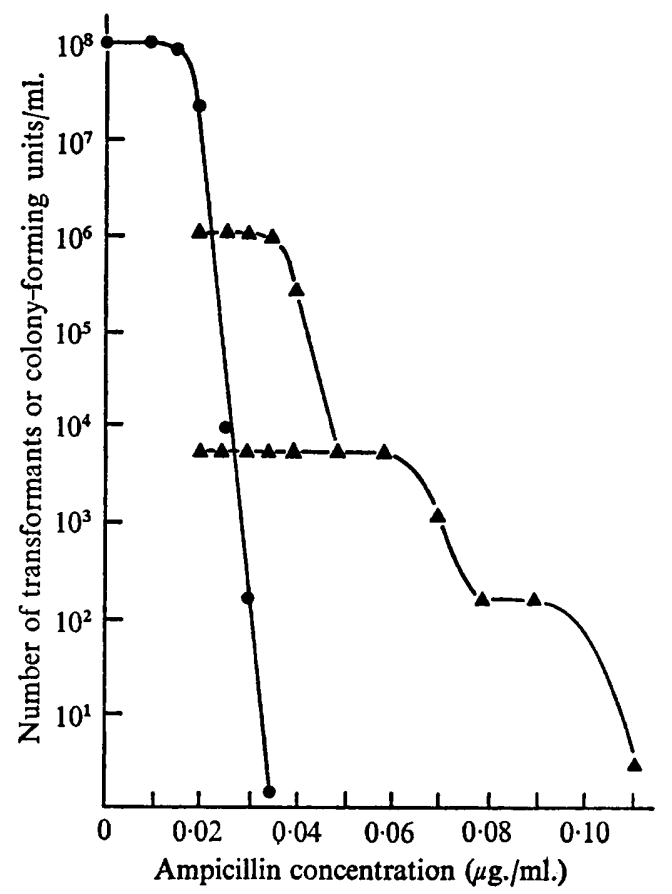

Fig. I. Transformation of strain $\mathrm{Cl} 3$ to ampicillin resistance by DNA from strain Amp 3 . ๑, Sensitivity curve of strain $\mathrm{Cl} 3 ; \boldsymbol{\Delta}$, ampicillin-resistant transformants.

At dilutions which allowed both 03 (i.e. Amp 03) and 06 (Amp 06) transformants to form colonies on the same plate, Amp 06 could be distinguished from Amp 03 by their much larger colony size. This explains the projection back, in Fig. I, of the Amp 06 curve to concentrations below $0.03 \mu \mathrm{g}$./ml.

Expression time. In the first instance, the expression times at the 03 and 06 levels were investigated by crossing strain $\mathrm{Cl} 3$ with 09 -DNA. The double layer technique always gave the full number of transformants even at zero time, and hence expression was allowed in the reaction tube after a $4 \mathrm{~min}$. exposure to the DNA followed by treatment with DNAse for I min. Samples were then plated at intervals directly into nutrient agar containing ampicillin at concentrations of $0.03 \mu \mathrm{g} . / \mathrm{ml}$. and $0.05 \mu \mathrm{g} . / \mathrm{ml}$. Full expression was complete at about 4 to $5 \mathrm{~min}$. for the 03 transformants and $9 \mathrm{~min}$. for the 06 transformants. The curves obtained are shown in Fig. 2.

These expression times are very short, and it was considered that they may be artifacts. It seemed possible that the ampicillin was not exerting an immediate effect 
on the organism, either because (a) competent organisms or organisms being transformed were insensitive to ampicillin, or $(b)$ the ampicillin required a period of time before the bacteriocidal action occurred with perhaps a period of bacteriostatic activity, allowing expression to occur.

Action of ampicillin on transforming organisms. To test the effect of ampicillin on a culture which was in the process of being transformed, strain $\mathrm{Cl}_{3}$ was exposed to $\mathrm{r}_{2} \mathrm{SQ}$ DNA for 4 min., treated with DNAse for I min. and ampicillin at concentrations of

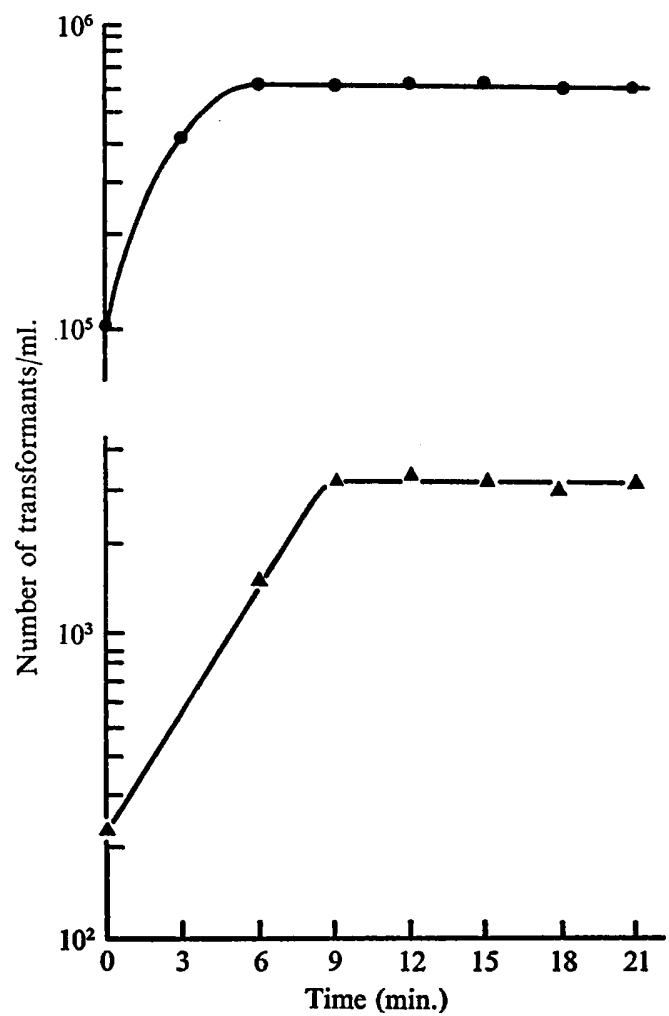

Fig. 2. Apparent expression curves of genes conveying ampicillin resistance to the $03 \mu \mathrm{g} . / \mathrm{ml}$. and $06 \mu \mathrm{g} . / \mathrm{ml}$. levels in the cross $\mathrm{cl} 3 \times($ Amp 3). O, Transformants to Amp 03 as singles; $\Delta$, transformants to Amp 06 as doubles.

$0.03 \mu \mathrm{g} . / \mathrm{ml} ., 0.06 \mu \mathrm{g} . / \mathrm{ml}$. and $0.09 \mu \mathrm{g} . / \mathrm{ml}$. were added. Samples were then plated in agar at intervals, given full expression for streptomycin resistance $(2 \mathrm{hr})$ before overlaying with streptomycin agar. Maximum numbers of streptomycin transformants were obtained until is to 20 min. exposure to the ampicillin, when the number of transformants dropped, indicating that the organisms were insensitive to the bacteriocidal action of the ampicillin up to that time. Furthermore, there was no effect by the ampicillin during the first 5 min. after the end of the DNAse treatment so that the rise seen at the early part of the curve in Fig. 2 was a true increase in the number of transformants with increase in the time of expression. It was possible that a bacteriostatic action of the ampicillin occurred which was negated on plating in the ampicillin-free medium. However, a culture of strain $\mathrm{Cl} 3$ prepared in exactly the same way (i.e. to produce 
competence) but not treated with DNA gave a growth curve showing a doubling of the number of colony-forming units for the first 15 to $20 \mathrm{~min}$. followed by a fairly rapid drop. This showed that there was no bacteriostatic action at the earlier exposure times, and that the bacteriocidal action occurred only after $20 \mathrm{~min}$. exposure. This culture was competent at the time of exposure to the ampicillin but a non-competent culture tested in the same way gave essentially similar results.

From these results it can be concluded that the expresson times of 4 to $5 \mathrm{~min}$. for the 03 transformants and $9 \mathrm{~min}$. for the 06 transformants are apparent times and must be increased by the 15 to $20 \mathrm{~min}$. necessary for the ampicillin to exert its effect under these conditions. The procedure adopted for scoring for ampicillin transformants is to allow exposure of the recipient organism to the DNA for 15 to $30 \mathrm{~min}$. and then to plate aliquots directly into nutrient agar containing ampicillin.

Table I. Resistance levels in $\mu \mathrm{g} . / \mathrm{ml}$. of ampicillin transformants appearing at frequencies corresponding to singles, doubles and triples

\begin{tabular}{|c|c|c|c|c|}
\hline \multirow[b]{2}{*}{ Recip. } & \multirow{2}{*}{$\begin{array}{l}\text { Donor } \\
\text { DNA }\end{array}$} & \multicolumn{3}{|c|}{$\begin{array}{l}\text { Resistance level }(\mu \mathrm{g} . / \mathrm{ml} .) \text { of } \\
\text { ampicillin transformants }\end{array}$} \\
\hline & & Singles & Doubles & Triples \\
\hline $\mathrm{Cl}_{3}$ & Amp 09 & 0.03 & 0.06 & 0.09 \\
\hline $\mathrm{Cl} 3$ & Amp o6 & 0.03 & 0.06 & - \\
\hline $\mathrm{cl} 3$ & Amp 03 & 0.03 & - & - \\
\hline Amp 03 & Amp 06 & 0.06 & - & - \\
\hline Amp o3 & Amp 09 & 0.06 & 0.09 & - \\
\hline Amp o3 & Amp 03 & - & - & - \\
\hline Amp 06 & Amp 09 & 0.09 & - & - \\
\hline Amp o6 & Amp 03 & - & - & - \\
\hline
\end{tabular}

Table 2. Apparent expression times of the 06 and 09 genes as single or double transformants

\begin{tabular}{|c|c|c|}
\hline \multirow[b]{2}{*}{ Cross } & \multicolumn{2}{|c|}{ Apparent expression time (min. } \\
\hline & Singles & Doubles \\
\hline 3 & $4-5(03)^{*}$ & $9(06)$ \\
\hline Imp o9) & $4-5(06)$ & $10(09)$ \\
\hline Amp 06> & $5(09)$ & 一 \\
\hline
\end{tabular}

* Figures in parentheses give the resistance level of the transformants.

Crosses between the ampicillin transformants. The single, double and triple transformants obtained by the cross $\mathrm{Cl} 3 \times(\mathrm{Amp}$ 09) were isolated and lysates of the strains prepared. Crosses were then made using these lysates as donors and strain $\mathrm{Cl} 3$ or the resistant transformants as receptors. The results obtained are summarized in Table $\mathrm{x}$. The higher levels of resistance could not be obtained as single transformants from $\mathrm{Cl}_{3}$, but could be obtained by using as recipient the transformant having a resistance one step lower than that of the donor DNA. Similarly, resistances at the og level could be obtained at doubles frequency in the cross Amp 03 $\times$ (Amp 09). Hence, the higher resistances are the result of the organism possessing two or more of the genes conferring ampicillin resistance. The 06 level requires two genes, and the 09 level requires three genes.

Expression of the 06 and og levels as singles and doubles. The apparent expression times for transformation to the 06 and 09 levels as single or double transformants were 
determined in the same manner as described above. The results are summarized in Table 2. Both the 06 and 09 genes when transformed as singles have the same apparent expression time as the 03 gene transformed as a single into $\mathrm{Cl}_{3}$, whilst the 09 gene transformed as a double had the same time as the 06 gene with $\mathrm{Cl} 3$, as recipient.

\section{DISCUSSION}

The results show that Amp 3 contained three loci conveying resistance to ampicillin which, although transmitted independently (i.e. are unlinked), are dependent on each other in a sequential fashion for the manifestation of the higher resistance levels. The lowest level of resistance, 03 , was obtained at the frequency of single transformants in the cross $\mathrm{Cl} 3 \times(\mathrm{Amp} 09)$, whereas 06 was obtained at doubles frequency and 09 at trebles frequency. Furthermore, in the cross Amp $03 \times($ Amp 09), 06 was obtained at singles frequency and 09 at doubles frequency. Hence resistance at the 06 level could not be obtained in the absence of the 03 gene, and the 09 level could not be obtained in the absence of both 03 and 06 genes.

Amp 06 transformed $\mathrm{Cl} 3$ to give both Amp 03 and Amp 06 as transformants, and Amp 09 transformed Amp 03 to give both Amp o6 and Amp 09. Hence, the pneumococci show the presence of three unlinked genes conferring resistance to ampicillin, namely (a) $a m p-A$ conferring resistance to $0.03 \mu \mathrm{g} . / \mathrm{ml}$., (b) $a m p-B$, which in the presence of $a m p-A$ confers resistance to $0.06 \mu \mathrm{g} . / \mathrm{ml}$. and (c) $a m p-C$ conferring resistance to $0.09 \mu \mathrm{g} . / \mathrm{ml}$. provided the organism also possesses $a m p-A$ and $a m p-B$. Strains possessing the latter two systems are similar to strain $r_{4}$ of Schaeffer (I956), a pneumococcus which, although resistant to $50 \mu \mathrm{g}$. streptomycin $/ \mathrm{ml}$., gave a transformant in the first instance resistant to $10 \mu \mathrm{g}$. $/ \mathrm{ml}$. which was then transformed by the same DNA to the full resistance of $50 \mu \mathrm{g} . / \mathrm{ml}$. The sulphonamide system described in pneumococcus by Hotchkiss \& Evans (1958) however is very different; in this case the three individual markers $a, b$, and $d$ potentiated each other to give higher resistances but each marker itself could be transformed as single units. The penicillin-resistant mutants of pneumococcus described by Hotchkiss(I95I) were similar to our ampicillinresistant mutants in the sense that the DNA from the penicillin-resistant mutants transformed to resistance levels lower than that of the donor DNA. However, they were very different in that no transformations to the highest resistance level possessed by the donor DNA were described even after further transformation on a resistant transformant. Also, the expression time of the penicillin mutants was more than $90 \mathrm{~min}$.

It is worth noting that the three resistance loci were produced in the same organism by a single mutagenic treatment by NNG.

As suspected, the very short expression times of 4 to $5 \mathrm{~min}$. were found to be artifacts due to the delay in the manifestation of the ampicillin action. Even so, an expression time of 20 to $25 \mathrm{~min}$. is still short when compared to the other resistance markers known in pneumococcus, such as $70 \mathrm{~min}$. for opt-r2, $90 \mathrm{~min}$. for ery-r2 and $120 \mathrm{~min}$. for $s t r-4 I$. It is interesting to note that the apparent expression times become the same for all three loci when being transformed as singles or as doubles, the time for the singles being about half that of the doubles. Hence it would appear that the second marker in the double transformants could not be expressed until after the first marker had completed an essential step in its expression. 
Nester (1964) showed that competent cultures of Bacillus subtilis were insensitive to penicillin, from which it was deduced that such cultures were not dividing, and it is believed that they are in a latent state. The results concerning the effect of ampicillin on the pneumococcal competent culture show that these cultures are not similar to the $B$. subtilis cultures in this respect since a doubling in the colony-forming units of the competent culture occurred first, followed by a rapid drop to I \% survival after $50 \mathrm{~min}$. exposure to the ampicillin.

Thanks are due to the Medical Research Council for a grant to support this work.

\section{REFERENCES}

Avery, O. T., MacLeod, C. M. \& MCCARTy, M. (1944). Studies on the chemical nature of the substance inducing transformation of pneumococcal types. Induction of transformation by a desoxyribonucleic acid fraction isolated from Pneumococcus type III. Journal of Experimental Medicine 89, 137.

BUTLER, L. O. (1965). A co-precipitation method for the preparation of transforming DNA from small samples of low density bacterial cultures. Journal of General Microbiology 39, 247.

EpHRUSSI-TAYLOR, H. (195I). Transformations allogènes du pneumocoque. Experimental Cell Research 2, 589.

HotchKiss, R. D. (1951). Transfer of penicillin resistance in pneumococci by the desoxyribonucleate derived from resistant cultures. Cold Spring Harbor Symposia on Quantitative Biology 16, 457.

Hotchiss, R. D. \& Evans, A. H. (1958). Analysis of the complex sulfonamide resistance locus of pneumococcus. Cold Spring Harbor Symposia on Quantitative Biology 23, 85.

Nester, E. W. (1964). Penicillin resistance of competent cells in deoxyribonucleic acid transformation of Bacillus subtilis. Journal of Bacteriology 87, 867.

RAVIN, A. W. \& IYER, V. N. (196I). The genetic relationship and phenotypic expression of mutations endowing pneumococcus with resistance to erythromycin. Journal of General Microbiology 26, 277.

SevaG, M. G., Lackman, D. B. \& Smolens, J. (1938). The isolation of the components of streptococcal nucleoproteins in serologically active form. Journal of Biological Chemistry 124, 625.

SCHAeffer, P. (1956). Analyse génétique de la résistance à la streptomycine chez le pneumocoque. Annales de l'Institut Pasteur, Paris 91, 323.

SiCARD, A. M. (1965). A new synthetic medium for Diplococcus pneumoniae, and its use for the study of reciprocal transformation at the Ami-A locus. Genetics, Princeton 50, 3I. 